\title{
Cambio del uso del suelo de la Sub Cuenca del Rio Mocal, Lempira, utilizando SIG y Teledetección, comprendido del año de 1988 al 2000.
}

Yessica Yamileth Sosa Reyes

\section{Resumen}

Este estudio se enmarca en dar a conocer como, a través de las tecnologías de la información geográfica como la Teledetección y los Sistemas de Información Geográfica, son punto de partida para el desarrollo de actividades encaminadas a mejorar las condiciones de los Recursos Naturales, y resuelven considerablemente con los resultados información para tomar decisiones que contribuyen el Ordenamiento Territorial.

Para el desarrollo de este estudio se utilizaron imágenes satelitales del sensor Landsat, recolectado imágenes comprendidas entre los años 1988, 1998 y 2000, las que fueron debidamente corregidas para obtener a través de una clasificación no supervisada, la cuantificación del cambio del uso del suelo del Rio Mocal, en el departamento de Lempira.

Los cambios del uso del suelo fueron evidentes como resultado se observó que bosque Latífoliado va en aumento en un $18 \%$, el bosque mixto en un $37 \%$, el matorral tubo un aumento del $7 \%$, el pasto tubo un descenso y la agricultura se mantiene en su rango.

Palabras Clave: Usos del suelo, imágenes, teledetección, Sistemas de Información Geográfica.

Yessica Yamileth Sosa Reyes, (yessica.sosa@unah.edu.hn, yessica.sosa04@gmail. com), Departamento de Ciencia y Tecnología de la Información Geográfica, Faculta de Ciencias Espaciales, Universidad Nacional Autónoma de Honduras. Teléfono 22394948. 


\section{Introducción}

El desarrollo de esta investigación se enmarca en el analizar los cambios del uso del suelo de la Sub cuenca del Rio Mocal, Lempira, mediante la interpretación digital de imágenes satelitales de tipo Landsat 5 y 7, de los años 1988, 1998 y 2000, realizando clasificación no supervisa, obteniendo como resultados tasas de cambio de del uso del suelo en los tres periodos de tiempo, desarrollando cartografía que muestra los cambios en el uso del suelo que ocurrieron en ese periodo de tiempo.

Con este estudio se pretende que las organizaciones insertas en la zona de la Sub cuenca del Rio Mocal como la FAO, ICF, Municipalidades, organizaciones de segundo grado entre otras interesadas en la sostenibilidad de los recursos naturales de la zona, tenga insumos necesarios para la toma de decisiones para el pago por servicios ambientales a través de técnicas de mejoramiento de las condiciones ambientales como lo es el Ordenamiento Territorial a través de tecnologías de la Información Geográfica.

En los municipios del sur del departamento de Lempira, de acuerdo a el programa PESA-FAO HN, ha venido realizando varias actividades encaminadas a la conservación, sostenibilidad y el manejo de los recursos naturales, prácticas como la disminución de las quemas agrícolas, aumento de la cobertura, disminución de la erosión y de la tala, así como el aumento a la producción y de la biodiversidad, lo que ha contribuido convincentemente al aumento del caudal en los ríos que abastecen al Rio Lempa.

En la subcuenca del Rio Mocal no existe información geoespacial del uso del suelo en el periodo de 12 años que demuestre que ha sido perjudicial o satisfactorio para el desarrollo de la subcuenca.

Para lograr este objetivo es necesario conocer los elementos cartográficos y temáticos que permitan analizar el cambio del uso del suelo, y que este análisis conlleve a crear una herramienta necesaria en la toma de decisiones para el manejo sostenible de los recursos naturales a través de un criterio de Ordenamiento territorial.

\section{Metodología}

El enfoque de este proyecto se basará en un enfoque cuantitativo en donde se esperan obtener características que ahondan los cambios ocurridos en el 
periodo de 12 años con evaluaciones de los años 1988, 1988 y 2000. Utilizando estadísticas de las variables de tiempo y tipo de suelo, teniendo como resultado adicional a estos cambios un análisis probabilístico de casusa-efecto. Mediante un proceso secuencial que varía de acuerdo a los tres años de análisis, deductivo de acuerdo a las observaciones visuales en el terreno y observaciones visuales en las imágenes satelitales y probatorio de los diferentes tipos de uso del suelo en los tres periodos de tiempo establecidos para esta investigación.

Este proyecto de investigación se basa en un tipo de estudio no experimental ya se observaran los fenómeno tal y como ocurren naturalmente de los usos del suelo en la Subcuenca del Rio Mocal.

Para realizar esta investigación la metodología utilizara los siguientes instrumentos detallados en las diferentes actividades que se describen a continuación:

Para el logro de los objetivos de este estudio se pretende realizar el análisis del cambio del uso del suelo para el Ordenamiento Territorial, mediante la aplicación de tecnologías de la Información Geográfica, a través de imágenes de satélite. Se utilizarán imágenes de satélite tipo LANDSAT de diferentes años (1988, 1998 y 2000) apoyándose del programa especializados para el Procesamiento y análisis de la Imagen y el procesamiento de la cartografía digital a través de programas especializados en sistemas de información geográfica. (Programas proporcionados por el laboratorio de pregrado del departamento de ciencia y tecnología de la información geográfica)

Se realizarán observaciones geo-referenciadas de campo, documentando con fotografías el estado actual del uso del suelo (Agricultura, Bosques, Plantaciones, Áreas ganaderas, cursos de agua, entre otros).

Para ello se plantean diferentes etapas de la investigación definidas de la siguiente manera:

- Selección del área de Estudio

- Para este estudio se tomará en cuenta la sub cuenca del Rio Mocal,

- Selección de Imágenes satelitales tipo LANDSAT de la Zona de estudio

- En este proceso se entrará a la página oficial de GLOVIS (http://glovis.usgs. gov/) para la obtención de las imágenes satelitales, ya procesadas, correspondientes a la zona y del periodo de 1988, 1998 y 2000. 
- Procesamiento Digital de las imágenes

Se aplicarán los procesos de correcciones geométricas, radiométricas, entre otras que ayuden a mejorar la calidad y evaluación de las coberturas de la tierra y del suelo.

- Interpretación visual de imágenes

- La interpretación visual de las imágenes para determinar los cambios de la cobertura de la tierra y uso del suelo, así como cuantificar esos cambios.

- Levantamiento de datos y validación en campo

- Que serán elementos para la identificación de puntos estratégicos para determinar los cambios del suelo y sus posibles causas de ese cambio.

- Interpretación y análisis de resultados

- Comparación de las imágenes satelitales.

- Detección de cambios del uso del suelo de las imágenes satelitales de la cuenca del Rio Mocal.

- Elaboración de Mapas de Cobertura de Usos del Suelo.

Esta metodología basada en el análisis Multitemporal de teledetección (Chuvieco, 2002).

La población y muestra definida para este estudio es: el uso del Suelo

\section{Resultados obtenidos}

\section{- FASE I: Definición del Área de Estudio}

En base a la metodología establecida se realiza el siguiente análisis:

En la realización de esta fase se tomó en cuenta la participación de diferentes miembros de la sociedad de los municipios verdes del sur de Lempira y Ocotepeque, así mismo se contó con la participación de Instituciones relacionadas al Manejo de los Recursos Naturales como ser: El Programa Especial para la Seguridad Alimentaria (PESA), el Instituto de Conservación Forestal, Áreas protegidas y Vida Silvestre (ICF), la Mancomunidad de Municipios del Parque Nacional (Ver figura 1). 


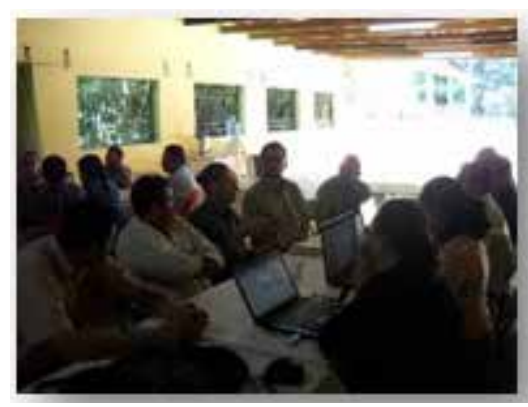

Figura 1. Reunión de trabajo para selección de área de estudio

Montaña de Celaque (MAPANCE), Cooperación Alemana (GIZ), Comité Central Pro Agua para el desarrollo Integral de Lempira (COCEPRADIL), EL Instituto Técnico Comunitario (ITC), Miembros de las Municipalidades de la Subcuenca del Rio Mocal, entre otros de Interés.

Se analizaron entre todos los participantes sobre cuál es el área prioritaria para desarrollar el análisis del cambio del Uso del Suelo, lo cual se llegó a la conclusión sería la de toda la Subcuenca del Rio Mocal que desemboca al Rio Lempa, por su interés ambiental, económico y social.

\section{- Delimitación del Área de Estudio}

Determinada el área de interés se procede mediante la técnica de delimitación de Cuencas, Sub Cuencas y/o Microcuencas, el cual se desarrolla mediante la línea divisoria de la Sub cuenca con ayuda de una red Hídrica de ríos que confluencia al Rio Mocal y una red de Curvas a nivel que con ayuda de un programa especializado se delimita utilizando la herramienta de creación de Shapefiles para disminuir el error de acuerdo a su fotografía a lo que común mente se le llama delimitación por el parte aguas (Ver figura2) 

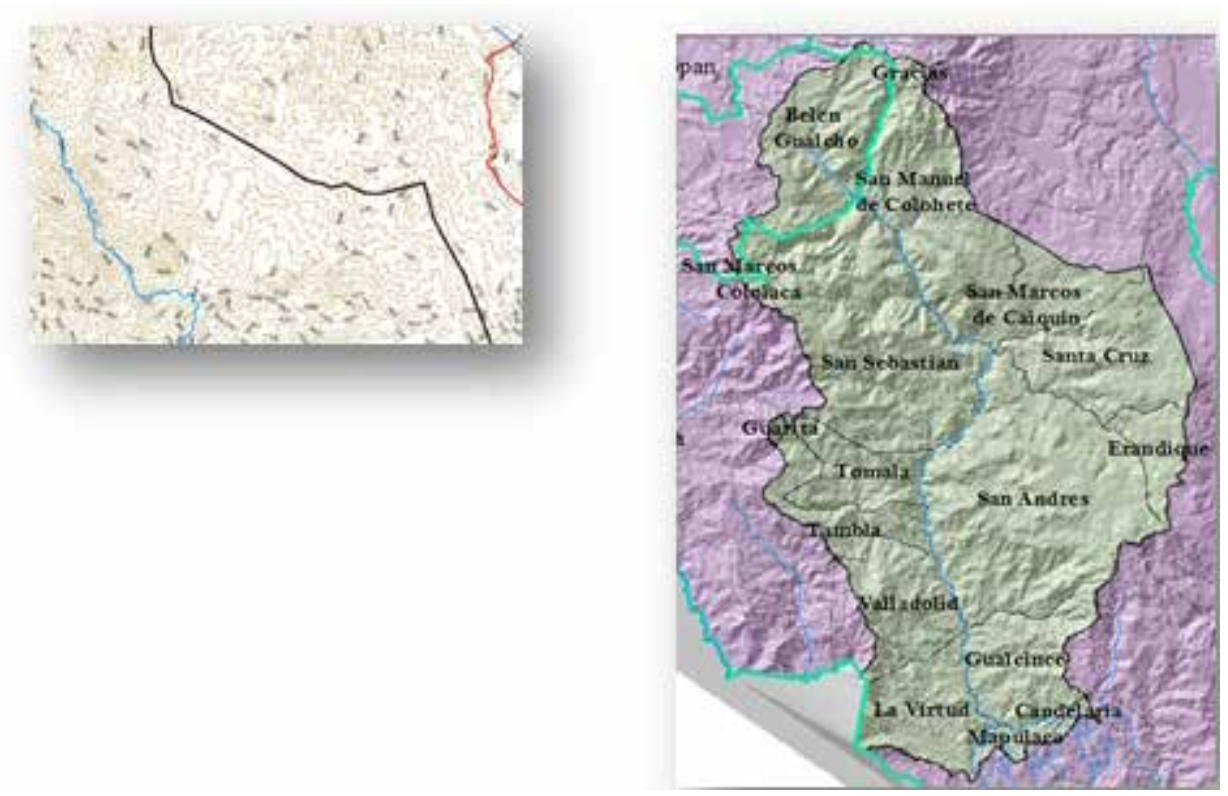

Figura 2 y 3 . Delimitación de Área de Estudio

Teniendo como resultado el área de influencia de la Sub cuenca del Rio Mocal Figura con la inclusión de los 18 municipios los cuales se desglosan en el cuadro 1.

Haciendo un total de 1190.004 km2

\begin{tabular}{r|l|l|r|r|r|r|r|}
\hline OBJECTID & GEOCODIGO & \multicolumn{1}{|c|}{ NOMBRE } & Area_Mocal & Shape_Area & SEX_H & SEX_M & E \\
\hline 178 & 130100 & Gracias & 6893360.28285 & 449054321.155 & 15908 & 15514 & \\
\hline 180 & 130300 & Candelaria & 4086067.76503 & 53198597.7189 & 2951 & 3041 \\
\hline 181 & 130400 & Cololaca & 3050037.07669 & 225357053.819 & 2807 & 2594 \\
\hline 182 & 130500 & Erandique & 29175131.4794 & 296660521.078 & 5794 & 5632 \\
\hline 183 & 130600 & Gualcince & 71410662.5578 & 162780511.977 & 4715 & 4593 & \\
\hline 184 & 130700 & Guarita & 2614713.41612 & 180342835.285 & 3970 & 3799 & \\
\hline 189 & 131200 & La Virtud & 68221453.0431 & 88965642.4045 & 2946 & 3032 \\
\hline 191 & 131400 & Mapulaca & 12808371.8932 & 32489439.643 & 1884 & 1888 \\
\hline 193 & 131600 & San Andres & 245706559.187 & 246831236.281 & 5264 & 4960 \\
\hline 196 & 131900 & San Manuel Colohete & 124476783.146 & 182941272.387 & 5419 & 5236 \\
\hline 198 & 132100 & San Sebastian & 2061944333.271 & 221954101.068 & 4098 & 3737 \\
\hline 199 & 132200 & Santa Cruz & 96556582.3992 & 151348024.396 & 2501 & 2314 \\
\hline 201 & 132400 & Tambla & 43655661.3845 & 58569090.9099 & 1142 & 1115 \\
\hline 202 & 132500 & Tomala & 47659807.0195 & 47659807.0195 & 2673 & 2503 \\
\hline 203 & 132600 & Valladolid & 63304878.8717 & 78310748.9438 & 1777 & 1776 & \\
\hline 205 & 132800 & San Marcos de Caiquin & 62130687.7055 & 96581008.8698 & 2112 & 1928 & \\
\hline 207 & 140200 & Belen Gualcho & 97863338.841 & 156387451.786 & 5709 & 5636 & \\
\hline 218 & 141300 & San Marcos & 4240659.48864 & 169224322.962 & 6832 & 7197 & \\
\hline & & & & & &
\end{tabular}

Cuadro 1. Listado de Municipios en Subcuenca del Rio Mocal 


\section{FASE II. Selección de imágenes Satelitales y Correcciones Básicas}

\section{Selección de imágenes Satelitales}

El periodo de análisis del cambio del Uso del suelo de la Subcuenca del Rio Mocal comienza en el año de 1988, periodo en el cual da como inicio el proyecto Lempira sur en donde se pretende identificar como era el estado de la Cobertura y Uso del suelo de la Subcuenca del Rio Mocal, pasando por un periodo de 10 años, 1998, momento antes del acontecimiento atmosférico como lo fue el Huracán Mitch, seguido del comportamiento ante este fenómeno en el año 2000. Conociendo todas estas características y definiendo cual sería el recurso disponible, se seleccionaron las imágenes del Sensor Landsat el cual teniendo en cuenta que el comiendo de este análisis parte del año de 1988, lo cual son las únicas imágenes satelitales que contienen este tipo de información.

Actualmente se encuentran activos el landsat 5 Thematic mapper (TM), 7 EnhancedThematicMapperPlus ETM+ y 8, los que son administrados por la NASA (National Space and Space Administration), en tanto que la producción y comercialización de las imágenes depende del Servicio Geológico de Estados Unidos (USGC). Las imágenes Landsat están compuestas por 7, 8 y hasta 11 bandas espectrales, que fueron elegidas especialmente para el monitoreo de la vegetación, para aplicaciones geológicas, para el estudio de los recursos naturales.

En este sentido se procede a la selección de imágenes disponibles en el servido de GLOVIS, el cual proporciona imágenes gratuitas en especial las de tipo Landsat, se procede a su descarga, teniendo como resultado 4 imágenes las cuales se describen y se muestran a continuación (Ver Figuras 4, 5 y 6) (Cuadro 2):

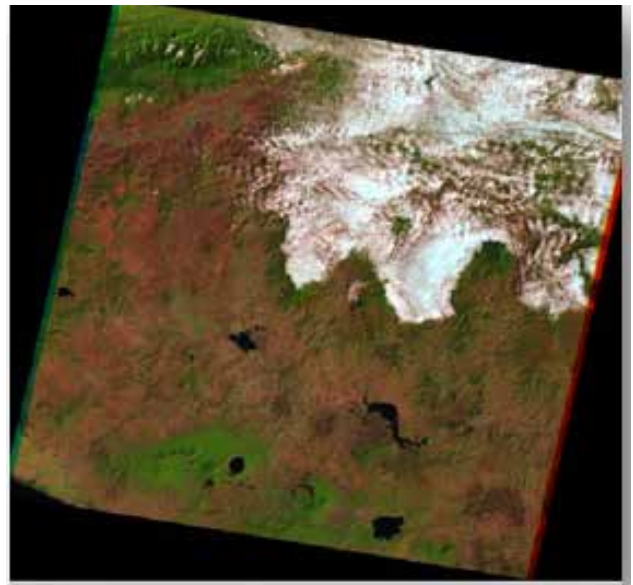


Figura 4. Imagen año 1988

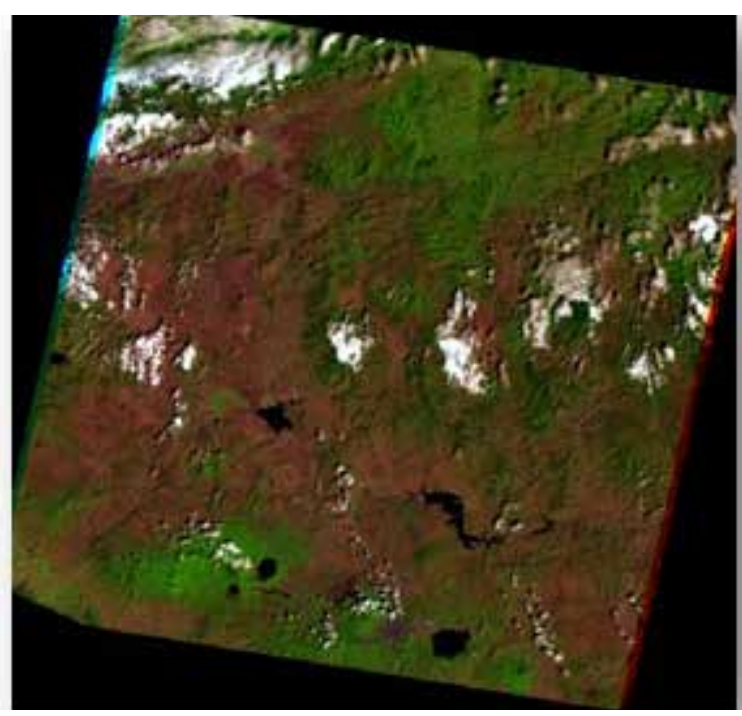

Figura 5. Imagen año 1998

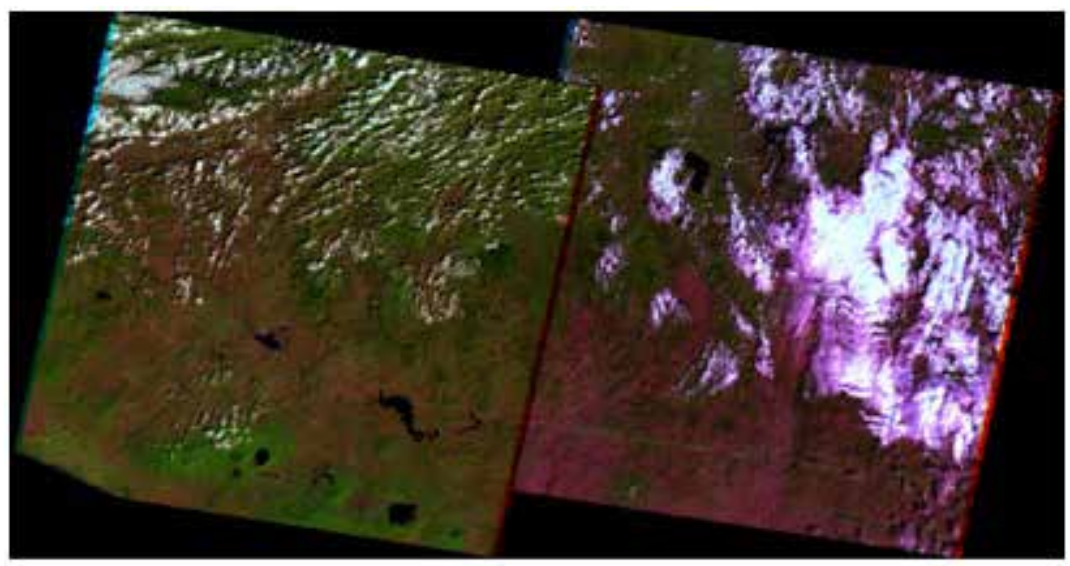

Figura 6. Imagen año 2000 


\begin{tabular}{|c|c|c|}
\hline Número Imagen & Tipo de Sensor & Fecha \\
\hline LT40190501988031XXX08 & Landsat 4 & $1988 / 01 / 31$ \\
\hline LT50190501998034AAA01 & Landsat 5 & 1998/03/02 \\
\hline LE70180502000025EDC00 & Landsat 7 & $2000 / 01 / 25$ \\
\hline LT50190502000008XXX02 & Landsat 5 & $2000 / 01 / 08$ \\
\hline
\end{tabular}

Cuadro 2. Características de las Imágenes descargadas

\section{Correcciones Básicas}

\section{Corrección Geométrica}

La corrección geométrica consiste en el proceso de ajuste de una imagen incluyen cualquier cambio en la posición que ocupan los pixeles que la forman. Por contraposición con las correcciones radiométricas, modificando únicamente la posición (coordenadas).

Este proceso se corrige mediante la evaluación el error geométrico de la imagen a partir de una serie de puntos con coordenadas conocidas a partir de una imagen previamente corregida mediante puntos de control realizados en campo, a partir de lugares o características que han perdurado por años como ser puentes, iglesias o carreteras, los cuales se les denomina puntos de control.

Como lo muestra la imagen las correcciones geométricas se realizan en el programa ERDAS a partir de la imagen 2000 en donde previamente se verifica y corrige con puntos tomados en campo.

Calculo de Radiancia

Este es un término muy genérico, que designa aquellas técnicas que modifican los ND (Numero Digital de cada Pixel) originales, con objeto de acercarlos a los que habría presentes en la imagen (Chuvieco, 2012) (Ver Figura 7) 


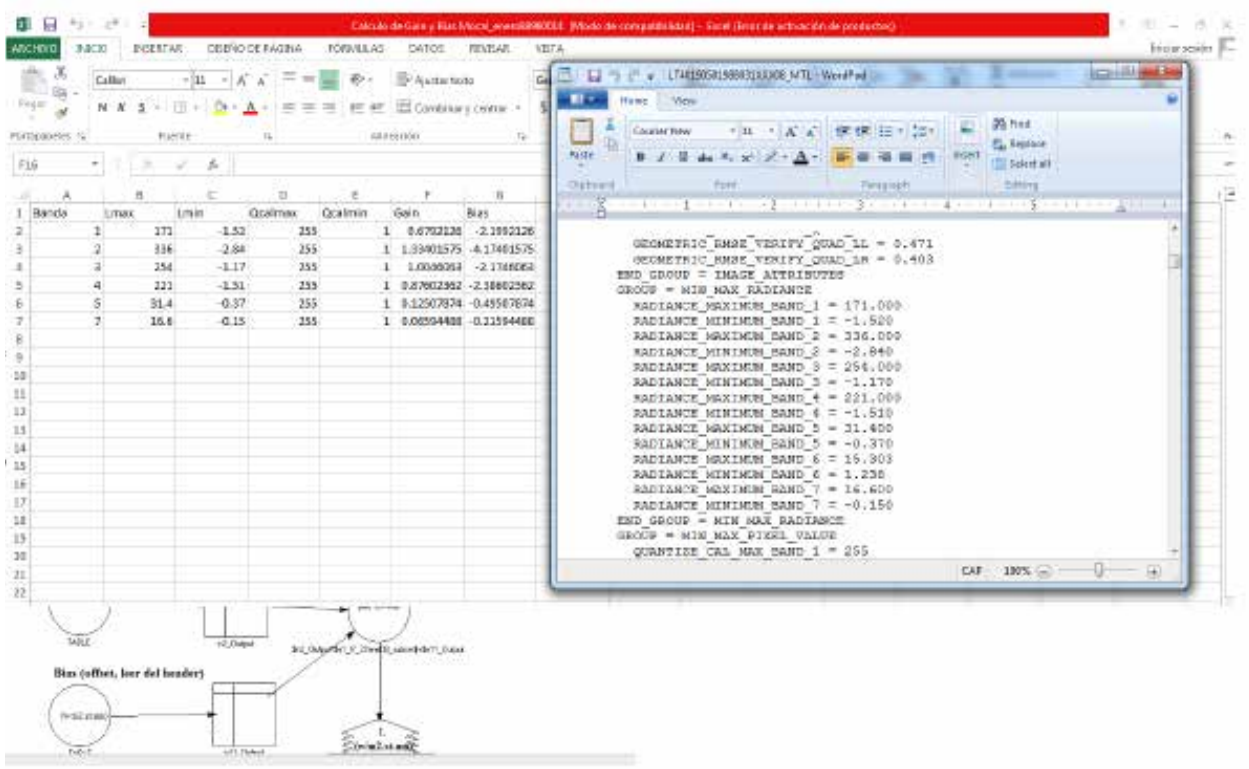

Figura 7. Proceso para el cálculo de Radiancia (IAFE, 2005)

\section{Corrección Atmosférica}

El procedimiento para abordar estas correcciones con exactitud es muy laboriosos y requieren datos sobre las condiciones de la atmosfera en el momento de tomar la imagen, que no suelen estar disponibles. Para ello se generó el procedimiento mediante modelos físicos de transferencia radiativa, que suele basarse en una serie de atmosferas estándar.

\section{FASE III Clasificación}

- Clasificación no supervisada (K-Medias)

Es una técnica multivariante que permite agrupar los casos o variables de un archivo de datos en función del parecido o similaridad existente de ellos. Esta técnica se desarrolla en el programa ERDAS Imagine 2013, el cual requiere de su procedimiento para pasar a la clasificación no supervisada. 
- Reconocimiento y validación en campo

Efectuar giras de campo en las que se capturen información de las diferentes coberturas de la tierra y usos del suelo en diferentes puntos de la Sub cuenca del Rio Mocal. Una vez teniendo los resultados resulta obligatorio verificar la calidad de los mismos, mediante una tabulación cruzada o matriz de confusión, el cual para verificar una imagen clasificada, la recogida de la imagen de referencia y la extracción del valor de la imagen permitirá obtener un listado de puntos de verificación, para los que poseemos tanto su cobertura real como la deducida por la clasificación (Ver cuadro 3). 


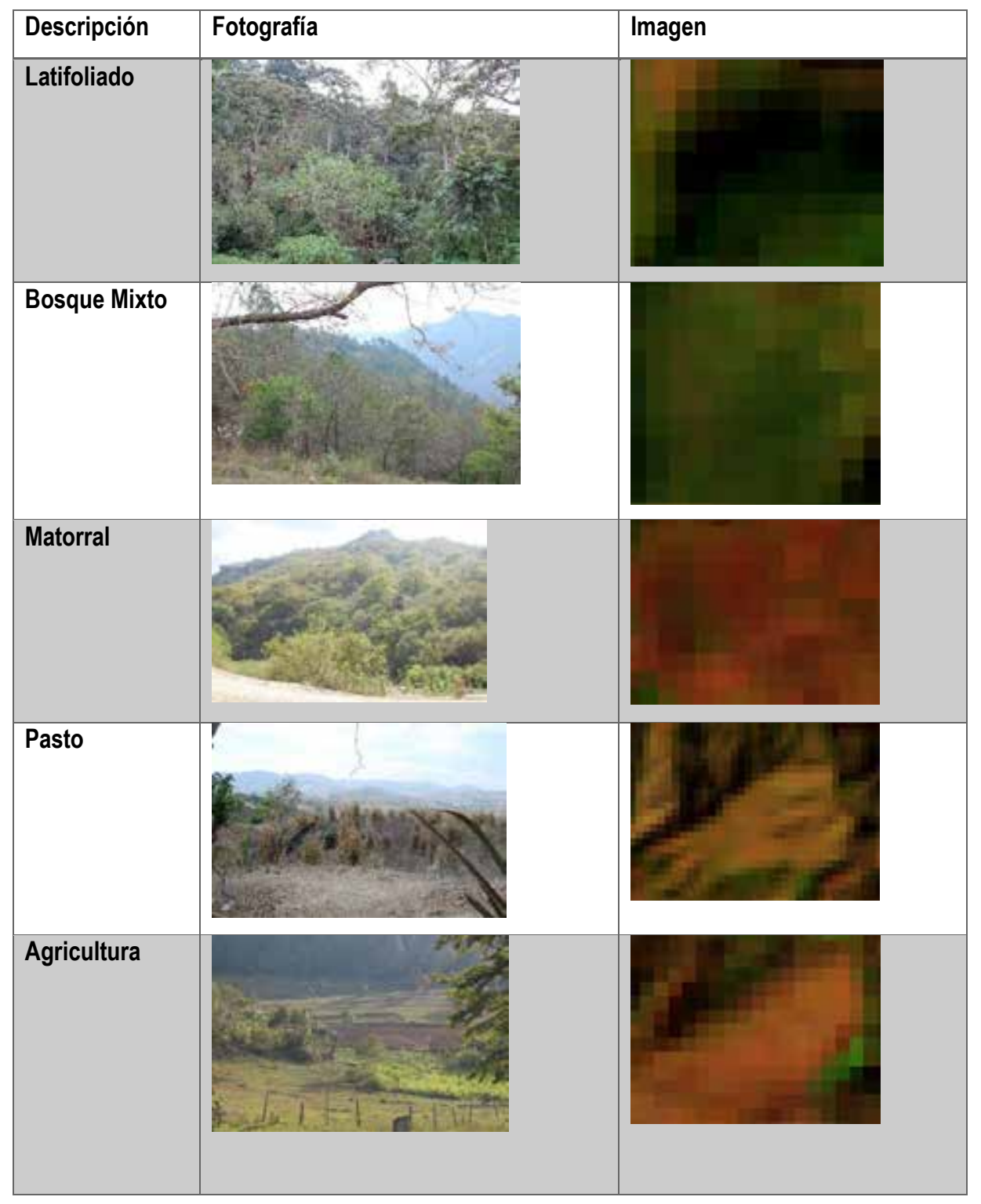

Cuadro 3. Descripción de la cobertura 
Resultado de la Clasificación de las imagines
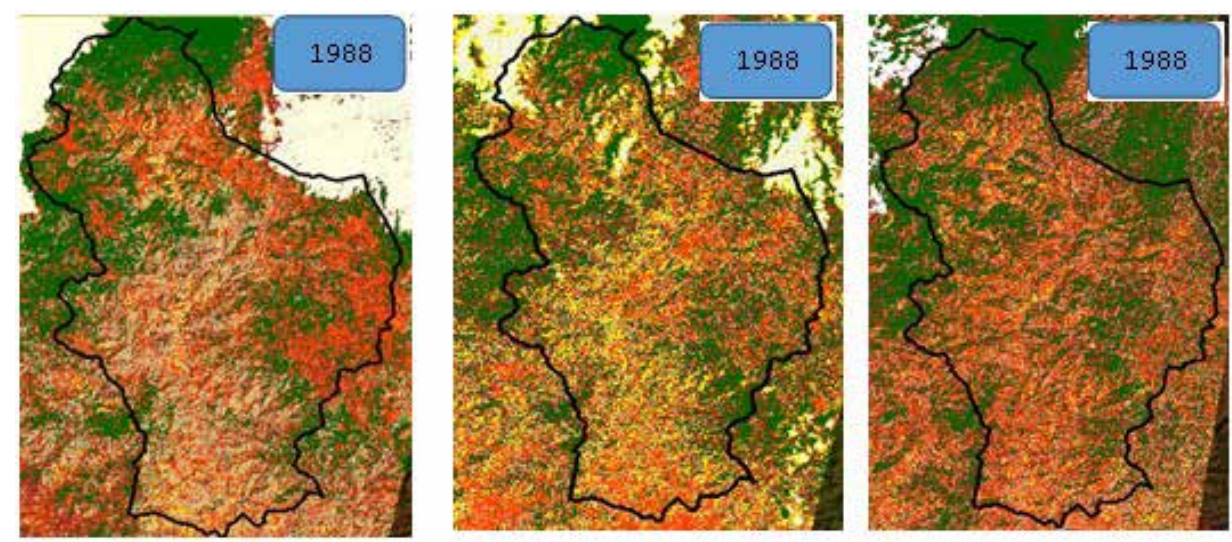

Figura8.Resultado de asignación de clases a cada una de las Imágenes

\begin{tabular}{|l|r|r|r|}
\hline \multicolumn{4}{|c|}{ Cuadro resumen de cambios del Uso del Suelo por Año en Hectáreas } \\
\hline Tipo de Uso & 1988 & 1998 & 2000 \\
\hline Bosque Latifoliado & M2 & M2 & M2 \\
\hline Bosque Mixto & 342628200 & 368080200 & 295653600 \\
\hline Matorral & 211787100 & 195590700 & 589847400 \\
\hline Pasto & 292105800 & 289348200 & 206707500 \\
\hline Agricultura & 288741600 & 191195100 & 72562500 \\
\hline Nubes & 33972300 & 124479900 & 25301700 \\
\hline TOTAL & 20838600 & 21379500 & 0 \\
\hline \multicolumn{3}{|c|}{ Cuadro resumen de cambios del Uso del Suelo por Año en Hectáreas } \\
\hline
\end{tabular}




\section{Conclusiones}

- Es evidente que con solo la clasificación no supervisada que se le dio a cada imagen, lo cambios que han ocurrido en los años 1988, 1998 y 2000, se aprecia que realmente existen cambios.

- En cuadro resumen se aprecia los cambios en el caso del Bosque Latifoliado está teniendo un descenso, significando que las coberturas de bosque Latifoliado han disminuido en un $13 \%$ con respecto a la cobertura que existía en el Año de 1988, en donde las intervenciones de la FAO aun no estaban establecidas.

- En cambio en el Bosque Mixto el porcentaje de cobertura aumento en más del $100 \%$ lo que nos indica que la cobertura del bosque Mixto está ganando áreas que quizá en su momento fueron o destinados a la agricultura o ganando áreas ya sea de agricultura o matorral.

- Las áreas de Pasto igualmente presenta un aumento de más del $100 \%$.

- Y en cuanto a la Agricultura, al inicio del 88' presenta una área bastante acaparada, debido a la principal actividad de la zona como lo es agricultura teniendo un descenso de más del 100\% entre los años de 1988 y 1998, mas sin embargo en el año 2000 aumenta en un $25 \%$ con respecto al año inicial.

\section{Recomendaciones}

- Se recomienda hacer el estudio más profundo en donde se muestren las pérdidas y ganancias de la Sub cuenca, creando criterios de cambios positivos y negativos en cuando a los usos del suelo de la zona.

- También se recomienda abundar en cuanto conocer cuáles han sido las causas que han provocado esos cambios en el uso que se le ha dado al suelo, conocer de parte de la población si esos cambios han sido significativos en el desarrollo de las comunidades insertas en la sub cuenca del Rio Mocal.

\section{Bibliografía}

- Emilio Chuvieco, S. (2002). Teledetección Ambiental, la Observación de la Tierra desde el Espacio. Barcelona, España: Ariel. 
- IAFE, S. d. (2005). Protocolo para el procesamiento de Imagenes Satelitales para Aplicaciones de la Administracion de Parques Nacionales. Buenos Aires, Argentina.

- REDDICCADIGIZ, P. (2011). TIPOS DE BOSQUES Y CONTEXTO DEL MAPEO DE LA COBERTURA FORESTAL. Obtenido de http://www.reddccadgiz. org/documentos/doc_1170376601.pdf 